\title{
ESP Culture System
}

National Cancer Institute

\section{Source}

National Cancer Institute. ESP Culture System. NCI Thesaurus. Code C88114.

A non-radiometric, broth-based growth system for determining Mycobacterium avium complex drug susceptibilities. 